\title{
Cranial nerve involvement in patients with MOG antibody-associated disease
}

Alvaro Cobo-Calvo, MD, PhD, Xavier Ayrignac, MD, PhD, Philippe Kerschen, MD, Philippe Horellou, PhD, Francois Cotton, MD, PhD, Pierre Labauge, MD, PhD, Sandra Vukusic, MD, PhD, Kumaran Deiva, MD, PhD, Ché Serguera, $\mathrm{MD}, \mathrm{PhD}$, ${ }^{*}$ and Romain Marignier, $\mathrm{MD}, \mathrm{PhD}^{*}$

Neurol Neuroimmunol Neuroinflamm 2019;6:e543. doi:10.1212/NXI.0000000000000543

\author{
Correspondence \\ Dr. Marignier \\ romain.marignier@chu-lyon.fr
}

\begin{abstract}
\section{Objective}

To describe clinical and radiologic features of cranial nerve $(\mathrm{CN})$ involvement in patients with myelin oligodendrocyte glycoprotein antibodies (MOG-IgG) and to assess the potential underlying mechanism of $\mathrm{CN}$ involvement using a nonhuman primate (NHP) model.
\end{abstract}

\section{Methods}

Epidemiologic, clinical, and radiologic features from a national cohort of 273 MOG-IgGpositive patients were retrospectively reviewed for $\mathrm{CN}$ involvement between January 2014 and January 2018. MOG-IgG binding was evaluated in CNS, CN, and peripheral nerve tissues from NHP.

\section{Results}

We identified 3 MOG-IgG-positive patients with radiologic and/or clinical CN involvement. Two patients displayed either trigeminal or vestibulocochlear nerve lesions at the root level, and the remaining patient had an oculomotor nerve involvement at the root exit and at the cisternal level. Additional CNS involvement was found in all 3 patients. None of the 3 patients' sera recognized MOG expression in $\mathrm{CN}$ of NHP.

\section{Conclusion}

Craneal nerve involvement can coexist in patients with MOG antibody disease, although the underlying pathophysiology remains elusive.
*These authors contributed equally to the manuscript.

From the Service de neurologie (A.C.-C., S.V., R.M.), sclérose en plaques, pathologies de la myéline et neuroinflammation and Centre de référence pour les maladies inflammatoires rares du cerveau et de la moelle (MIRCEM)- Hôpital Neurologique Pierre Wertheimer Hospices Civils de Lyon, France; Lyon Neuroscience Research Center (A.C.-C., R.M.), U1028 INSERM, UMR5292 CNRS, FLUID Team, Lyon, France; Service de sclérose en plaques (X.A., P.L.), Hôpital Universitaire de Montpellier, France; Service de Neurologie (P.K.), Centre hospitalier de Luxembourg; Inserm (P.H.), U 1184, Center for Immunology of Viral Infections and Autoimmune Diseases, Université Paris-Sud 11, CEA, DSV/iMETI, Division of ImmunoVirology, IDMIT, Faculté de médecine, Le Kremlin-Bicêtre Cedex, France; Service de Radiologie (F.C.), Centre Hospitalier Lyon-Sud, Hospices Civils de Lyon, Pierre-Bénite, France; Université Claude Bernard Lyon 1 (F.C., S.V., R.M.), F-69100 Villeurbanne, France; Lyon's Neuroscience Research Center (S.V.), Observatoire Français de la Sclérose en Plaques, INSERM 1028 et CNRS UMR5292, Lyon, France; Service de neurologie pédiatrique (K.D.), Centre de référence pour les maladies inflammatoires rares du cerveau et de la moelle, Le KremlinBicêtre, France; and INSERM US27 MIRCen (C.S.), CEA, Fontenay-aux-Roses, France.

Funding information and disclosures are provided at the end of the article. Full disclosure form information provided by the authors is available with the full text of this article at Neurology.org/NN. 


\section{Glossary}

AQP4 = aquaporin-4; $\mathbf{C N}=$ cranial nerve; $\mathbf{h M O G}=$ human MOG; $\mathbf{M B P}=$ myelin basic protein; $\mathbf{M F I}=$ mean fluorescence intensity; MOG = myelin oligodendrocyte glycoprotein; $\mathbf{M T P}=$ methylprednisolone; NHP = nonhuman primate; NMOSD = neuromyelitis optica spectrum disorder; OCB = oligoclonal band; OFSEP = Observatoire Français de la Sclérose en Plaques; $\mathbf{R T}=$ room temperature.

Antibodies against myelin oligodendrocyte glycoprotein (MOG-IgG) are a well-recognized cause of demyelination in adults and children with acute disseminated encephalomyelitis ${ }^{1,2}$ and neuromyelitis optica spectrum disorders (NMOSDs). ${ }^{3-6}$ New clinical phenotypes such as cortical encephalitis, brainstem syndromes, ${ }^{7-10}$ and fulminant cases ${ }^{10,11}$ have been more recently reported, suggesting that the clinical and radiologic presentation of MOG antibody-associated disease could be broader than previously thought. Cranial nerve $(\mathrm{CN})$ involvement in patients with serum MOG-IgG has not been described so far.

We report here clinical and radiologic features of 3 MOGIgG-positive patients with $\mathrm{CN}$ involvement. To evaluate the possible underlying mechanism of MOG-IgG in the present clinical phenotype, we screened patients' sera for reactivity in the $\mathrm{CNS}, \mathrm{CN}$, and peripheral nerve from nonhuman primate (NHP) (cynomolgus macaque).

\section{Methods}

\section{Patients}

Epidemiologic, clinical, and radiologic data were retrospectively reviewed from the adult $(\mathrm{n}=197)^{10}$ and pediatric $(\mathrm{n}=$ 76) French cohorts of MOG-IgG-positive patients diagnosed between January 2014 and January 2018.

MRI was performed in the clinical setting including axial and sagittal images of the brain and spinal cord obtained by T1-, T2-, fluid attenuated inversion (FLAIR), and T1-weighted postcontrast sequences.

For experiments, sera from MOG-IgG-positive patients with $\mathrm{CN}$ involvement and controls were used. As controls, we selected 1 MOG-IgG-positive patient with an exclusive CNS involvement, 1 healthy control, and 1 double-seronegative (MOG and aquaporin-4 [AQP4]-IgG-negative) NMOSD patient.

\section{Standard protocol approvals, registrations, and patient consents}

The study was approved by the Ethics Committee of the University Hospital of Lyon, France. All patients provided their informed consent to participate in the study.

This study was conducted within the framework of Observatoire Français de la Sclérose en Plaques (OFSEP). Because of national confidentiality requirements, only anonymized data, not pseudonymized data, can be shared. Although anonymization techniques might result in impoverishment of data (Article 29 of Directive 95/46/EC, Opinion 05/2014 on Anonymization Techniques-0829/14/EN WP 216), data used for this study were only pseudonymized. However, access to OFSEP data to conduct a scientific project is possible by following the OFSEP data access process (ofsep.org/en/ data access) and with respect to French law.

\section{Autoantibody detection}

All samples were examined for IgG against human MOG (hMOG) and human AQP4 by cell-based assays. ${ }^{12,13}$ Briefly, for MOG antibodies, HEK293 cells were transfected with pEGFP-N1-hMOG plasmid (kindly provided by Markus Reindl, Innsbruck, Austria). After 48 hours, transfected cells were dissociated with Accutase (Sigma-Aldrich, A6964) and incubated with phosphate-buffered saline (PBS) $8 \%$ normal goat serum (NGS) for 30 minutes at room temperature (RT). Then, patients' sera diluted at 1:640 were incubated with transfected cells for 30 minutes at $4^{\circ} \mathrm{C}$. This cutoff was selected to avoid false-positive signal detected with healthy controls in previous studies. ${ }^{14}$ Cells were fixed with $1 \%$ paraformaldehyde (PFA) for 15 minutes and then incubated 20 minutes at RT in the dark with a secondary antibody allophycocyanin (APC)goat anti-human IgG-Fcr fragment-specific (1:100 dilution, Jackson ImmunoResearch 109-136-170).

For the detection of AQP4 autoantibody, HEK293 cells were transfected with pcDNA3.1-AQP4-M23 and pEGF-C1 plasmids with Lipofectamine LTX (Invitrogen 10573013). After 48 hours, cells were dissociated with Accutase (Sigma-Aldrich, A6964) and incubated with PBS $8 \%$ NGS for 30 minutes. After blocking, cells were incubated with patients' sera at 1:100 cells for 30 minutes at $4^{\circ} \mathrm{C}$ and then fixed with $1 \%$ PFA at RT for 15 minutes. HEK293 cells were incubated for 20 minutes at RT in the dark with a secondary antibody APC-goat anti-human IgG-Fc $\gamma$ fragmentspecific (1:100 dilution, Jackson ImmunoResearch 109-136170). FACS analysis for MOG and AQP4-IgG was performed with the CANTO II flow cytometer (Becton Dickinson).

In addition, serum samples were tested for antibodies against neuronal cell surface antigens using rat brain immunohistochemistry, as described previously. ${ }^{15}$

\section{Nonhuman primate tissue preparation and immunohistochemistry}

\section{Nonhuman primates}

Adult captive-bred 3- to 5-year-old female cynomolgus macaques (Macaca fascicularis) were used. ${ }^{16,17}$ Brains were 
sampled after intracardiac perfusion with PBS and 4\% PFA. Brains were postfixed by overnight immersion in $4 \%$ PFA and then transferred to PBS and embedded in paraffin. For immunohistochemistry analysis, 3 - to 5 - $\mu$ m-thick paraffin sections from brain, cerebellum, oculomotor, trigeminal, and sciatic nerves were cut and deparaffinized.

\section{Immunohistochemistry}

To assess myelin staining pattern in NHP tissues, IgGs were purified as previously described. ${ }^{18}$ Purified IgG from each patient were labeled with Alexa Fluor 594 (referred to as purified IgG-AF594) Microscale Protein Labeling Kit (Invitrogen; 30008), according to the manufacturer's instruction to prevent background signal associated with the use of secondary antihuman IgG antibodies in macaque brain tissues (nonpublished observations). To ascertain that the purified IgG-AF594 from MOG-positive patients still bound to MOG antigen, we performed flow cytometry cell-based assay and compared $\Delta$-mean fluorescence intensity (MFI), determined by the subtraction of MFI obtained with HEK293 control cells from that obtained with HEK293 MOG-positive cells. The levels measured for the 3 patients with $\mathrm{CN}$ involvement were at the same level as the one obtained with the positive control patient or above (figure e-1, links.lww.com/NXI/A97).

Purified IgG-AF594 from MOG-IgG-positive patients and controls were incubated with macaque tissue slices (diluted 1 : 20) for 1 hour and 30 minutes following 30 minutes of saturation with a block solution (BSA5\%, 10\% NGS). Myelin was also labeled with a commercial mouse monoclonal MOG antibody (clone 8-18C5, MAB5680; Millipore) as a positive control, and a biotinylated goat anti-mouse antibody (1:200, BA9200, Vector Laboratories, Burlingame, CA) was used as secondary, for 30 minutes at RT, followed by the avidin-biotinperoxidase complex (Vectastain Elite ABC Kit, PK 6100, Vector Laboratories, Burlingame, CA). Positive antigen-antibody reactions were visualized by incubation with 3,3-diaminobenzidine tetrahydrochloride $\mathrm{H}_{2} \mathrm{O}_{2}$ in 01 Mimidazole, $\mathrm{pH} 7.1$ for 5 minutes, followed by slight counterstaining with hematoxylin. A mouse monoclonal anti-myelin basic protein (MBP) was used to confirm myelin staining (dilution 1/200) (LS B2231, LifeSpan Bioscience), followed by a secondary goat anti-mouse antibody coupled to fluorochromes Alexa 488 (dilution 1/500) (A32731, Thermo Fisher Scientific). Labeled tissues were analyzed and pictured with confocal microscopy.

\section{Results}

\section{Patient clinical and radiologic characteristics}

We identified 3 ( 2 adult and 1 pediatric) MOG-IgG-positive patients with clinical or radiologic $\mathrm{CN}$ involvement.

\section{Patient Id.1}

A 76-year-old man with a medical history of hypertension and dyslipidemia developed insidiously general fatigue, and 1 month later a left facial numbness. Neurologic examination revealed left facial hypesthesia (ophthalmic, maxillary, and mandibular divisions) and dysmetria of the left arm. Brain MRI revealed FLAIR hyperintensities of both upper cerebellar peduncles with gadolinium enhancement (figure 1A). Left trigeminal nerve showed a gadolinium enhancement at the root level (figure 1B). CSF revealed $0.52 \mathrm{~g} / \mathrm{L}$ of proteins without cells or oligoclonal bands (OCBs). A whole-body 18-fluorodeoxyglucose PET/CT imaging showed no abnormalities. Symptoms improved spontaneously without treatment, and the patient did not receive any immunoactive drug. Six months later, a new right trigeminal nerve gadolinium enhancement was observed on a routine brain MRI without any new clinical involvement (figure 1C). Two years after onset, the patient remained asymptomatic and the brain MRI showed complete resolution of lesions (figure 1D).

\section{Patient Id.2}

A 16-year-old girl with a medical history of idiopathic congenital nystagmus presented with a 5-day history of fever, general mental alteration, and disorientation rapidly associated with dizziness and vomiting, suspected from infectious meningitis. Neurologic examination only found an already known nystagmus in all directions of gaze without other oculomotor disturbances. Lumbar puncture was performed, and she was immediately started on IV amoxicillin and acyclovir. CSF showed neither cells nor OCBs, and proteins and glucose were within the normal range. All viral PCR and bacterial cultures were negative, and IV treatment was stopped. Brain MRI revealed bilateral juxtacortical and supratentorial white matter hyperintensities on FLAIR (figure 1E). Gadolinium enhancement was observed on both third oculomotor nerves at the root exit and at the cisternal level (figure 1F). Spinal MRI revealed a T2 cervical hyperintensity with a subtle gadolinium enhancement (figure 1G). Three months later, a brain MRI scan showed an absence of gadolinium enhancement on the third nerve and partial resolution of the brain FLAIR hyperintensities with no gadolinium enhancement (figure $1 \mathrm{H}$ ). Four months later, she presented with a decrease in visual acuity on the right eye together with retro-orbital pain. Three days of IV methylprednisolone (MTP) $(1 \mathrm{~g} / \mathrm{d})$ was started with complete recovery. After 24 months of follow-up, the patient was asymptomatic.

\section{Patient Id.3}

A 52-year-old woman with hypertension, hypothyroidism, and chronic kidney disease was admitted for an 8-day history of diplopia, vertigo, and gait instability. Neurologic examination revealed a "one and a half syndrome", a positive Romberg sign, and dizziness. Blood test confirmed a renal insufficiency (creatinine $1.28 \mathrm{mg} / \mathrm{dL}$ and glomerular filtration rate $43 \mathrm{~mL} / \mathrm{min}$ ). CSF showed 27 leukocytes (65\% lymphocytes), $0.51 \mathrm{~g} / \mathrm{L}$ of proteins, normal glucose, and no OCBs. Brain MRI showed asymmetrical FLAIR hyperintensities at the medulla oblongata and pons and in the dorsal pontine tegmentum (figure 1I). A bilateral trigeminal and vestibulocochlear nerve gadolinium enhancement was found at the root level (figure 1, J-L). Spinal cord MRI showed no abnormalities. PET/CT imaging showed no hypermetabolic foci. The patient received 5 days of IV MTP $(1 \mathrm{~g} / \mathrm{d})$ with subsequent clinical recovery. After a follow-up of 12 months, the patient remained asymptomatic with no further treatment. 
Figure 1 Radiologic features of human myelin oligodendrocyte glycoprotein immunoglobulin G-positive patients with cranial nerve involvement
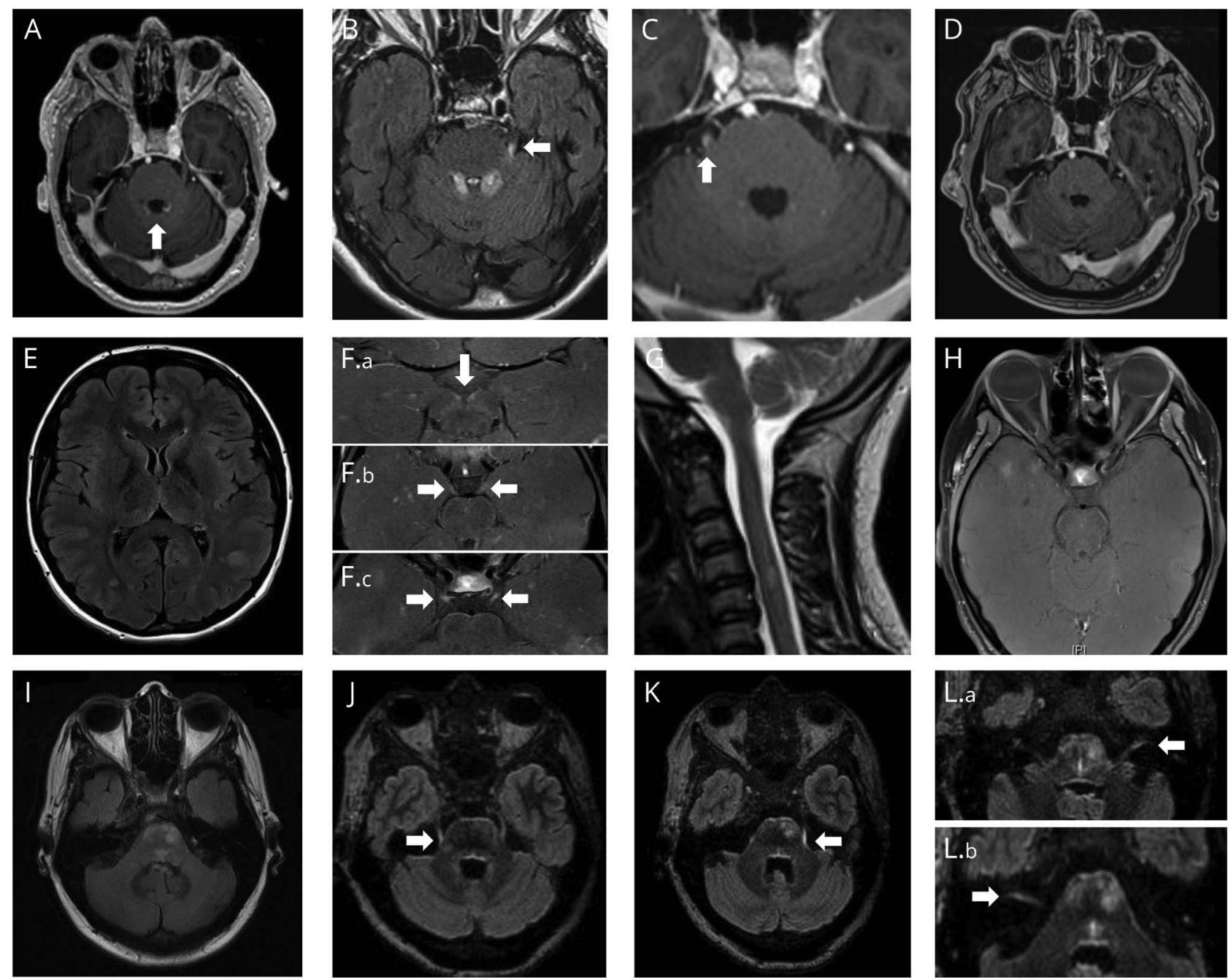

Patient Id.1 (A-D). (A) Bilateral upper cerebellar peduncle. (B and C) Left and right trigeminal nerve gadolinium enhancement on T1W postcontrast sequence. (D) Complete resolution of the lesions on T1 postgadolinium. Patient Id. $2(E-H)$. (E) White matter cerebral lesions on FLAIR sequences. (F, a-c), Bilateral oculomotor nerve gadolinium enhancement in the cisternal part of the nerve on T1W postcontrast sequence with fat saturation. (G) Focal cervical T2 lesion on spinal cord MRI. (H) Resolution of oculomotor gadolinium enhancement on T1W postcontrast sequence with fat saturation. Patient Id.3 (I-L). (I) Brainstem asymmetric FLAIR hyperintensities and dorsal pontine tegmentum hyperintensity. ( and K) Bilateral trigeminal nerve gadolinium enhancement on FLAIR postcontrast sequence. ( $L$, a and b), Bilateral vestibulocochlear nerve gadolinium enhancement on FLAIR postgadolinium sequence.

MOG-IgG were found positive in serum samples taken at 12 months after first symptoms in patient Id.1 and at onset in patients Id.2 and Id.3. None of the patients had AQP4IgG or additional antibodies against neuronal cell surface antigens.

\section{Tissue immunohistochemistry}

First, we analyzed by immunohistochemistry whether purified IgG-AF594 from the 3 patients with $\mathrm{CN}$ involvement reacted with NHP brain slices. Purified IgG-AF594 from all 3 patients allowed myelin staining on brain slices from NHP (table, figure $2 \mathrm{~A}$ ), with similar aspect as that obtained with commercial mouse monoclonal 8-18C5 anti-MOG (figure 2B). In addition, purified IgG-AF594 colocalized with the commercial MBP antibody (figure 2C).
Then, we evaluated whether purified IgG-AF594 of the 3 patients labeled NHP CN or peripheral nerves. None of the purified IgG-AF594 showed positive staining neither in proximal and distal regions of oculomotor, trigeminal, nor in distal regions of the sciatic nerve (figure 3). Equally, neither the purified IgG-AF594 from the MOG-IgG-positive patient with exclusive affection of CNS nor that of the healthy subject or the double-seronegative NMOSD control displayed any staining on trigeminal or sciatic nerves (not shown).

\section{Discussion}

In this study, we report clinical and/or radiologic involvement of CNs in MOG-IgG-positive patients, thus enlarging the clinical spectrum of MOG antibody-associated disease. 
Table Epitope recognition by human MOG among species in cell-based assays and immunohistochemistry

\begin{tabular}{|c|c|c|c|}
\hline \multirow[b]{2}{*}{ Patient identification } & \multirow{2}{*}{$\frac{\text { Cell-based assays }}{\text { Human MOG (1:640) }}$} & \multicolumn{2}{|c|}{ NHP immunohistochemistry } \\
\hline & & Brain & Cranial nerves \\
\hline Id.1 & Pos & MSP++ & Neg \\
\hline Id.2 & Pos & $\mathrm{MSP}++$ & Neg \\
\hline Id.3 & Pos & $\mathrm{MSP}++$ & Neg \\
\hline Control; MOG-IgG positive ${ }^{a}$ & Pos & $\mathrm{MSP}++$ & Neg \\
\hline Control; healthy subject & Neg & Neg & Neg \\
\hline Control; double-seronegative NMOSD & Neg & Neg & Neg \\
\hline
\end{tabular}

Abbreviations: $M O G$ = myelin oligodendrocyte glycoprotein; MSP = myelin staining pattern; Neg = negative; NHP = nonhuman primate; NMOSD = neuromyelitis optica spectrum disorder; Pos = positive.

Myelin staining pattern (MSP) was classified as Neg (no staining), + (when slightly), ++ (moderate), and +++ (intense pattern).

a The MOG-IgG-positive patient had exclusive involvement of the CNS.

MOG antibody-associated disease is a relatively new entity with a predisposition for the optic nerve and the spinal cord, with encephalic or brainstem structures being less frequently involved. $^{3-10}$ Among our national cohort of adult and pediatric MOG-IgG-positive patients, 3 of 273 patients (1.1\%) had clinical or radiologic involvement of $\mathrm{CNs}$, in addition to $\mathrm{CNS}$ involvement.

Figure 2 Nonhuman primate brain immunohistochemistry

A.a. Patients

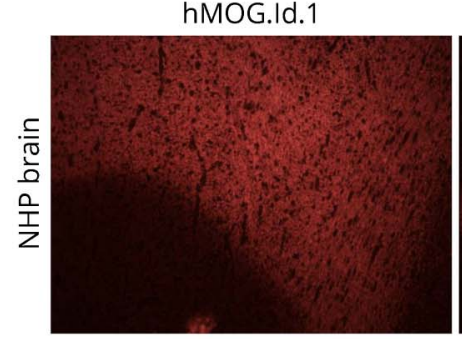

hMOG.Id.2

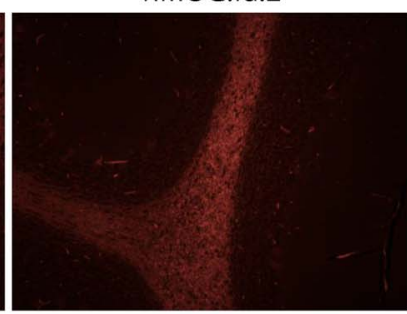

A.b. Controls

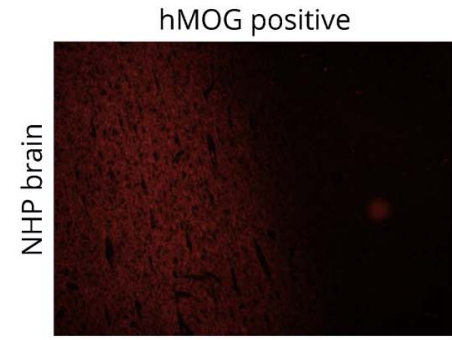

B. Monoclonal commercial MOG 8-18C5
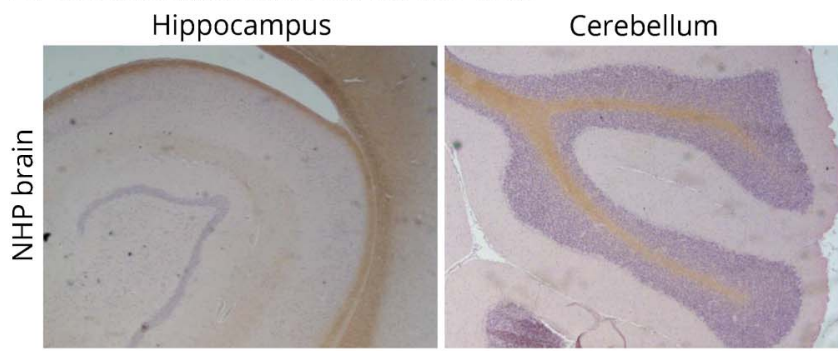

Subcortical white matter

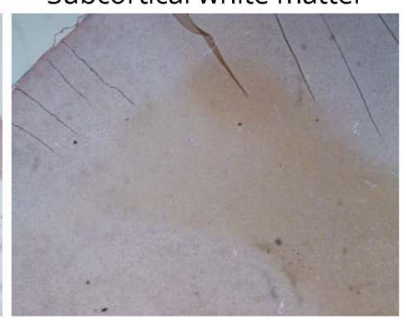

hMOG.Id.3

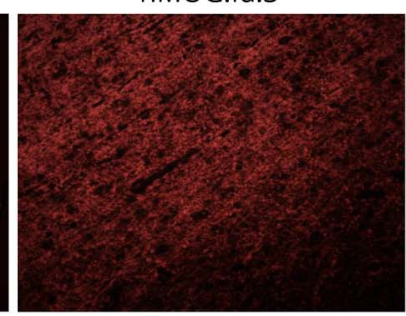

Healthy control

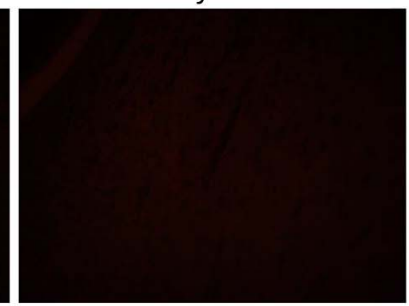

C. hMOG.Id.1/commerical MBP

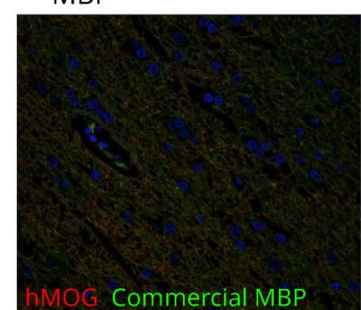

(A) Purified IgG-AF594 from patients (A.a) and from controls (A.b). (B) Brain and cerebellum nonhuman primate myelin staining with commercial monoclonal MOG 8-18C5. (C) Purified IgG-AF594 from patients colocalized with commercial anti-MBP. An example of patient Id.1. hMOG = human MOG; MBP = myelin basic protein; MOG = myelin oligodendrocyte glycoprotein; NHP = nonhuman primate. 
A. Trigeminal nerve

Dorsal root ganglion

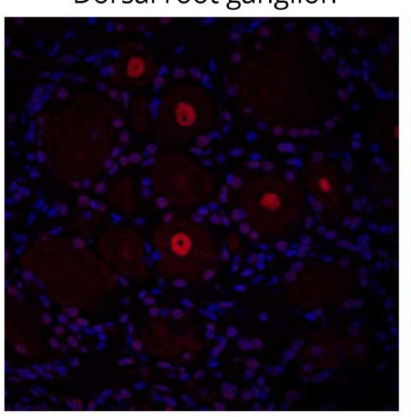

B. Sciatic nerve

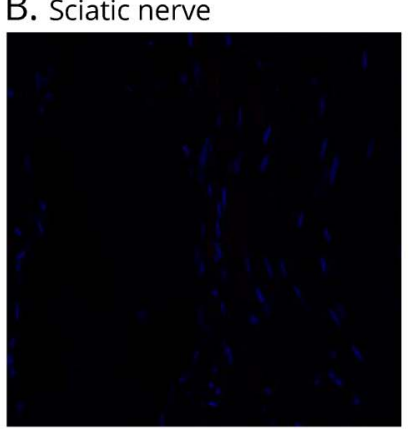

Proximal region

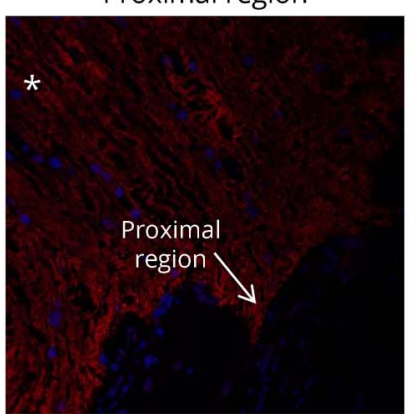

C. Oculomotor nerve

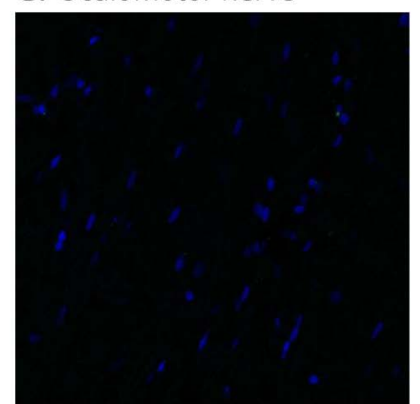

Distal region

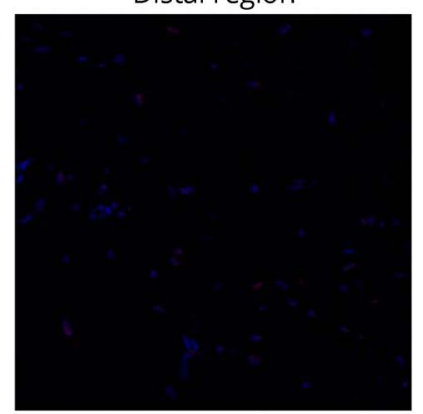

Purified IgG-AF594-IgG from patients staining in (A) trigeminal, (B) sciatic, and (C) oculomotor nerves. *Staining labeling MOG protein at the CNS region. MOG = myelin oligodendrocyte glycoprotein.
The 3 patients presented in this study had clinical symptoms or radiologic images related to the involvement of oculomotor, trigeminal, or vestibulocochlear nerves. Two patients displayed gadolinium enhancement of $\mathrm{CNs}$ at the transitional zone at the root level. Such region contains an overlap of central and peripheral myelin features whose extension differs among CNs, over 7 and $9 \mathrm{~mm}$ in length in trigeminal and vestibulocochlear nerves, respectively. ${ }^{19,20}$ On the contrary, the oculomotor nerve gadolinium enhancement in the third patient extended beyond the anticipated transitional zone between peripheral and central myelin. ${ }^{21}$

To study the underlying pathophysiology of the $\mathrm{CN}$ involvement, we used NHP tissues to evaluate MOG-IgG binding in $\mathrm{CNS}, \mathrm{CN}$, and peripheral nerve structures. We found that purified immunoglobulins from MOG-IgGpositive patients did not allow labeling neither in proximal nor in distal portions of $\mathrm{CNs}$ explored. Because $\mathrm{MOG}$ is a protein expressed by oligodendroctyes in the $\mathrm{CNS}^{22}$ the absence of MOG-IgG binding at the peripheral level in our NHP model was not unexpected. However, the absence of MOG recognition at the transitional zone by the serum of MOG-IgG patients did not permit to confirm a possible role of MOGIgG over this region. Such $\mathrm{CN}$ involvement could also be explained as the result of downstream inflammatory process from the intra-axial pontine lesion. We also may consider that the presence of other specific autoantibodies different from MOG-IgG or an unknown demyelinating process specifically targeting the peripheral nerve could be the cause of $\mathrm{CN}$ lesion rather than a restricted involvement of the transitional zone or a peripheral nerve involvement in continuation to a demyelinating process from the CNS.

We found that all patients showed a similar myelin staining pattern in the brain and cerebellar slices of NHP. Recent studies have shown that only a proportion of IgG from MOGIgG-positive patients could recognize epitopes shared by humans and rodents. ${ }^{7,23}$ Differences in MOG recognition among species is likely the consequence of a decreased homology in amino acid sequences of MOG with 19 different amino acids of 218 between the mouse and human, ${ }^{23,24}$ but only 5 between macaques and humans. The most frequent recognized MOG epitope by $\mathrm{hMOG}-\mathrm{IgG}$ resides at position 42 in the $\mathrm{CC}^{\prime}$ loop. ${ }^{25}$ The disparity on the type of amino acid at this position between human and rodents (proline in humans and serine in rodents) is largely responsible for the lack of epitope recognition between both species. ${ }^{24,25}$ However, this amino acid discrepancy does not exist in the MOG protein sequence between cynomolgus macaques and human who are phylogenetically closer. ${ }^{26}$ Thus, macaques are a suitable model to test autoantibodies from human autoimmune diseases and could be potentially useful when studying diseases such as MOG antibody-associated disease where the difference in the structure of the protein may lead to an absence of recognition by antibodies. ${ }^{17}$

Such inflammation of the peripheral nervous system has been reported in AQP4 antibody-positive NMOSDs. Different 
patterns of involvement have been described such as polyneuropathy, ${ }^{27,28}$ radiculopathy, ${ }^{29}$ myeloradiculitis, ${ }^{30}$ and second motor neuron involvement. ${ }^{31,32}$ Recently, vestibulocochlear nerve lesion as a part of $\mathrm{CN}$ involvement has been reported for the first time in NMOSDs. ${ }^{33}$ Moreover and similarly to our cases, involvement of the transitional region at the spinal root has also been described in a patient presenting with meningoradiculitis. ${ }^{30}$ In this case, histopathology showed a loss of AQP4 expression and demyelination, suggesting that the underlying pathophysiology could be explained by the presence of $\mathrm{AQP} 4$ protein location at the root level, thus being a target for AQP4-IgG. In MS, radiologic trigeminal nerve involvement has been described up to $2.9 \%$ of patients, ${ }^{34,35}$ being not always associated with clinical symptoms, as observed in our patients. ${ }^{35}$ In some cases, the lesion was also found in the cisternal region, distally from the trigeminal root entry zone. ${ }^{35,36}$ Recently, cisternal oculomotor nerve enhancement has been described in closely relation to the CNS demyelinating lesion. ${ }^{37}$ In all reported patients with the cisternal oculomotor or trigeminal nerve enhancement, ${ }^{35-37}$ an ancient or recent brainstem lesion was found, which suggests an extension from the CNS inflammation rather than a specific demyelination of the peripheral myelin. Some authors have pointed out that the active inflammation may persist longer in the peripheral nerve than in the CNS. ${ }^{35}$

Overall, our findings suggest that $\mathrm{CN}$ involvement can coexist in patients with MOG-antibody disease. However, the underlying pathophysiology remains to be elucidated.

\section{Acknowledgment}

The authors thank Dr. Albert Saiz (Center of Neuroimmunology, Hospital Clinic, Barcelona, Spain) for having performed different antibody testing and immunohistochemistry experiments. They also thank the group of NeuroBioTec from Hospices Civils de Lyon for supporting this study.

\section{Study funding}

This study was supported by a grant from the ARSEP Foundation and a grant provided by the French State and handled by the "Agence Nationale de la Recherche", within the framework of the "Investments for the Future" program, under the reference ANR-10-COHO-002 Observatoire Français de la Sclérose en Plaques (OFSEP), by the Eugene Devic Foundation against Multiple Sclerosis (EDMUS Foundation), and the patient association "Déchaine Ton Coeur".

Appendix 1 Author contributions

\begin{tabular}{|c|c|c|c|}
\hline Author & Location & Role & Contributions \\
\hline $\begin{array}{l}\text { Alvaro Cobo- } \\
\text { Calvo, MD, } \\
\text { PhD }\end{array}$ & $\begin{array}{l}\text { Hôpital Neurologique Pierre Wertheimer, Hospices Civils de Lyon, } \\
\text { Lyon }\end{array}$ & Author & $\begin{array}{l}\text { Study concept and design, performed experiments, } \\
\text { acquisition of data, analysis and interpretation, and } \\
\text { writing of the manuscript }\end{array}$ \\
\hline $\begin{array}{l}\text { Xavier } \\
\text { Ayrignac, } \\
\text { MD, PhD }\end{array}$ & $\begin{array}{l}\text { Multiple Sclerosis Clinic, Montpellier University Hospital, } \\
\text { Montpellier }\end{array}$ & Author & $\begin{array}{l}\text { Acquisition of data and critical revision of the manuscript } \\
\text { for important intellectual content }\end{array}$ \\
\hline $\begin{array}{l}\text { Philippe } \\
\text { Kerschen, } \\
\text { MD }\end{array}$ & $\begin{array}{l}\text { Service de Neurologie, Centre Hospitalier de Luxembourg, } \\
\text { Luxembourg }\end{array}$ & Author & $\begin{array}{l}\text { Acquisition of data and critical revision of the manuscript } \\
\text { for important intellectual content }\end{array}$ \\
\hline $\begin{array}{l}\text { Philippe } \\
\text { Horellou, } \\
\text { PhD }\end{array}$ & $\begin{array}{l}\text { Center for Immunology of Viral Infections and Autoimmune } \\
\text { Diseases, Division of Immuno-Virology, Le Kremlin-Bicêtre Cedex, } \\
\text { France }\end{array}$ & Author & $\begin{array}{l}\text { Performed experiments and critical revision of the } \\
\text { manuscript for important intellectual content }\end{array}$ \\
\hline $\begin{array}{l}\text { Francois } \\
\text { Cotton, MD, } \\
\text { PhD }\end{array}$ & $\begin{array}{l}\text { Centre Hospitalier Lyon-Sud, Hospices Civils de Lyon, Pierre- } \\
\text { Bénite, France }\end{array}$ & Author & $\begin{array}{l}\text { Critical revision of the manuscript for important } \\
\text { intellectual content }\end{array}$ \\
\hline $\begin{array}{l}\text { Pierre } \\
\text { Labauge, MD, } \\
\text { PhD }\end{array}$ & $\begin{array}{l}\text { Multiple Sclerosis Clinic, Montpellier University Hospital, } \\
\text { Montpellier }\end{array}$ & Author & $\begin{array}{l}\text { Acquisition of data and critical revision of the manuscript } \\
\text { for important intellectual content }\end{array}$ \\
\hline $\begin{array}{l}\text { Sandra } \\
\text { Vukusic, MD, } \\
\text { PhD }\end{array}$ & $\begin{array}{l}\text { Hôpital Neurologique Pierre Wertheimer Hospices Civils de Lyon, } \\
\text { Lyon }\end{array}$ & Author & $\begin{array}{l}\text { Critical revision of the manuscript for important } \\
\text { intellectual content }\end{array}$ \\
\hline $\begin{array}{l}\text { Kumaran } \\
\text { Deiva, MD, } \\
\text { PhD }\end{array}$ & Service de Neurologie Pédiatrique, Le Kremlin-Bicêtre, France & Author & $\begin{array}{l}\text { Acquisition of data and critical revision of the manuscript } \\
\text { for important intellectual content }\end{array}$ \\
\hline $\begin{array}{l}\text { Ché } \\
\text { Serguera, } \\
\text { MD, PhD }\end{array}$ & INSERM US27 MIRCen, CEA, Fontenay-aux-Roses, France & Author & $\begin{array}{l}\text { Study concept and design, performed experiments, } \\
\text { acquisition of data, analysis and interpretation, and } \\
\text { writing of the manuscript }\end{array}$ \\
\hline $\begin{array}{l}\text { Romain } \\
\text { Marignier, } \\
\text { MD, PhD }\end{array}$ & $\begin{array}{l}\text { Hôpital Neurologique Pierre Wertheimer, Hospices Civils de Lyon, } \\
\text { Lyon }\end{array}$ & Author & $\begin{array}{l}\text { Study concept and design, performed experiments, } \\
\text { acquisition of data, analysis and interpretation, and } \\
\text { writing of the manuscript }\end{array}$ \\
\hline
\end{tabular}




\section{Disclosure}

A. Cobo-Calvo, X. Avrignac, P. Kerschen, P. Horellou, F. Cotton, and P. Labauge report no disclosures. S. Vukusic served on the scientific advisory boards of and consulted for Biogen, Celgene, GeNeuro, Genzyme, MedDay, Merck Serono, Novartis, Roche, Sanofi-Aventis, and Teva; received travel funding and/or speaker honoraria from Biogen, Genzyme, Merck Serono, Novartis, Roche, Sanofi-Aventis, and Teva; and received research support from Biogen, Genzyme, MedDay, Merck Serono, Novartis, Roche, Sanofi-Aventis, and Teva. K. Deiva received travel funding from Biogen, Merck Serono, Genzyme, and Novartis. C. Serguera reports no disclosures. R. Marignier served on the scientific advisory board of MedImmune and received travel funding and speaker honoraria from Biogen, Genzyme, Novartis, Merck Serono, Roche, Sanofi-Aventis, and Teva. Full disclosure form information provided by the authors is available with the full text of this article at Neurology.org/NN.

\section{Publication history}

Received by Neurology: Neuroimmunology \& Neuroinflammation October 8, 2018. Accepted in final form December 7, 2018.

\section{References}

1. Baumann M, Sahin K, Lechner C, et al. Clinical and neuroradiological differences of paediatric acute disseminating encephalomyelitis with and without antibodies to the myelin oligodendrocyte glycoprotein. J Neurol Neurosurg Psychiatry 2015;86: 265-272.

2. Brilot F, Dale RC, Selter RC, et al. Antibodies to native myelin oligodendrocyte glycoprotein in children with inflammatory demyelinating central nervous system disease. Ann Neurol 2009;66:833-842.

3. Sato DK, Callegaro D, Lana-Peixoto MA, et al. Distinction between MOG antibodypositive and AQP4 antibody-positive NMO spectrum disorders. Neurology 2014;82: 474-481.

4. Höftberger R, Sepulveda M, Armangue T, et al. Antibodies to MOG and AQP4 in adults with neuromyelitis optica and suspected limited forms of the disease. Mult Scler 2015;21:866-874

5. Kitley J, Waters P, Woodhall M, et al. Neuromyelitis optica spectrum disorders with aquaporin-4 and myelin-oligodendrocyte glycoprotein antibodies: a comparative study. JAMA Neurol 2014;71:276-283.

6. Jurynczyk M, Messina S, Woodhall MR, et al. Clinical presentation and prognosis in MOG-antibody disease: a UK study. Brain 2017;140:3128-3138.

7. Sepúlveda M, Armangue T, Martinez-Hernandez E, et al. Clinical spectrum associated with MOG autoimmunity in adults: significance of sharing rodent MOG epitopes. J Neurol 2016;263:1349-1360.

8. Hamid SHM, Whittam D, Saviour M, et al. Seizures and encephalitis in myelin oligodendrocyte glycoprotein IgG disease vs aquaporin $4 \mathrm{IgG}$ disease. JAMA Neurol 2018;75:65-71.

9. Ogawa R, Nakashima I, Takahashi T, et al. MOG antibody-positive, benign, unilateral, cerebral cortical encephalitis with epilepsy. Neurol Neuroimmunol Neuroinflamm 2017;4:e322. doi: 10.1212/NXI.0000000000000322.

10. Cobo-Calvo A, Ruiz A, Maillart E, et al. Clinical spectrum and prognostic value of CNS MOG autoimmunity in adults: the MOGADOR study. Neurology 2018;90: e1858-e1869.

11. Di Pauli F, Höftberger R, Reindl M, et al. Fulminant demyelinating encephalomyelitis: insights from antibody studies and neuropathology. Neurol Neuroimmunol Neuroinflamm 2015;2:e175. doi: 10.1212/NXI.0000000000000175.
12. Cobo-Calvo Á, Ruiz A, D’Indy H, et al. MOG antibody-related disorders: common features and uncommon presentations. J Neurol 2017;264:1945-1955.

13. Marignier R, Bernard-Valnet R, Giraudon P, et al. Aquaporin-4 antibody-negative neuromyelitis optica: distinct assay sensitivity-dependent entity. Neurology 2013;80: 2194-2200.

14. Mader S, Gredler V, Schanda K, et al. Complement activating antibodies to myelin oligodendrocyte glycoprotein in neuromyelitis optica and related disorders. J Neuroinflammation $2011 ; 8: 184$.

15. Boronat A, Sabater L, Saiz A, Dalmau J, Graus F. GABA(B) receptor antibodies in limbic encephalitis and anti-GAD-associated neurologic disorders. Neurology 2011; 76:795-800.

16. Bitoun $\mathrm{S}$, Roques $\mathrm{P}$, Larcher $\mathrm{T}$, et al. Both systemic and intra-articular immunization with citrullinated peptides are needed to induce arthritis in the macaque. Front Immunol 2017;8:1816.

17. Stimmer L, Fovet CM, Serguera C. Experimental models of autoimmune demyelinating diseases in nonhuman primates. Vet Pathol 2018;55:27-41.

18. Marignier R, Ruiz A, Cavagna S, et al. Neuromyelitis optica study model based on chronic infusion of autoantibodies in rat cerebrospinal fluid. J Neuroinflammation 2016;13:111.

19. Peker S, Kurtkaya O, Uzün I, Pamir MN. Microanatomy of the central myelin-peripheral myelin transition zone of the trigeminal nerve. Neurosurgery 2006;59:354-359.

20. Pamir HA. Some histologic features of the cranial nerves. Arch Neurol Psychiatry 1931;25:356-372.

21. Fraher JP, Smiddy PF, O'Sullivan VR. The central-peripheral transitional regions of cranial nerves. Trochlear and abducent nerves. J Anat 1988;161:115-123.

22. von Büdingen HC, Tanuma N, Villoslada P, Ouallet SL, Hauser SL, Genain CP Immune responses against the myelin/oligodendrocyte glycoprotein in experimental autoimmune demyelination. J Clin Immunol 2001;21:155-170.

23. Peschl P, Schanda K, Zeka B, et al. Human antibodies against the myelin oligodendrocyte glycoprotein can cause complement-dependent demyelination. J Neuroinflammation 2017;14:208.

24. Mayer MC, Breithaupt C, Reindl M, et al. Distinction and temporal stability of conformational epitopes on myelin oligodendrocyte glycoprotein recognized by patients with different inflammatory central nervous system diseases. J Immuno 2013;191:3594-3604.

25. Marta CB, Oliver AR, Sweet RA, Pfeiffer SE, Ruddle NH. Pathogenic myelin oligodendrocyte glycoprotein antibodies recognize glycosylated epitopes and perturb oligodendrocyte physiology. Proc Natl Acad Sci USA 2005;102:13992-13997.

26. Delarasse C, Della Gaspera B, Lu CW, et al. Complex alternative splicing of the myelin oligodendrocyte glycoprotein gene is unique to human and non-human primates. J Neurochem 2006;98:1707-1717.

27. Warabi Y, Yamazaki M, Shimizu T, Nagao M. Abnormal nerve conduction study findings indicating the existence of peripheral neuropathy in multiple sclerosis and neuromyelitis optica. Biomed Res Int 2013;2013:847670.

28. Nagao M, Suzuki H, Ichihashi J, et al. Acute combined central and peripheral demyelination showing anti-aquaporin 4 antibody positivity. Intern Med 2012;51:2443-2447.

29. Kim S, Park J, Kwon BS, et al. Radiculopathy in neuromyelitis optica: how does antiAQP4 Ab involve PNS? Mult Scler Relat Disord 2017;18:77-81.

30. Takai Y, Misu T, Nakashima I, et al. Two cases of lumbosacral myeloradiculitis with anti-aquaporin-4 antibody. Neurology 2012;79:1826-1828.

31. Mingbunjerdsuk P, Katirji B. Acute cervical segmental denervation in neuromyelitis optica spectrum disorder. J Clin Neuromuscul Dis 2014;16:90-97.

32. Laemmer AB, Maihöfner C, Gölitz P, et al. Possible second motor neuron damage in neuromyelitis optica. Clin Neurophysiol 2014;125:859-861.

33. Bonnan M, Cabre P. Meningeal and vestibulocochlear nerve enhancement in neuromyelitis optica. Eur J Neurol 2017;24:e89-e90

34. van der Meijs AH, Tan IL, Barkhof F. Incidence of enhancement of the trigeminal nerve on MRI in patients with multiple sclerosis. Mult Scler 2002;8:64-67.

35. da Silva CJ, da Rocha AJ, Mendes MF, et al. Trigeminal involvement in multiple sclerosis: magnetic resonance imaging findings with clinical correlation in a series of patients. Mult Scler 2005;11:282-285.

36. Pichiecchio A, Bergamaschi R, Tavazzi E, et al. Bilateral trigeminal enhancement on magnetic resonance imaging in a patient with multiple sclerosis and trigeminal neuralgia. Mult Scler 2007;13:814-816.

37. Shor N, Amador MD, Dormont D, et al. Involvement of peripheral III nerve in multiple sclerosis patient: report of a new case and discussion of the underlying mechanism. Mult Scler 2017;23:748-750. 


\section{Neurology \\ Neuroimmunology \& Neuroinflammation}

\section{Cranial nerve involvement in patients with MOG antibody-associated disease}

Alvaro Cobo-Calvo, Xavier Ayrignac, Philippe Kerschen, et al.

Neurol Neuroimmunol Neuroinflamm 2019;6;

DOI 10.1212/NXI.0000000000000543

This information is current as of February 1, 2019

\section{Updated Information \& \\ Services}

References

Citations

Permissions \& Licensing

Reprints including high resolution figures, can be found at:

http://nn.neurology.org/content/6/2/e543.full.html

This article cites 37 articles, 3 of which you can access for free at: http://nn.neurology.org/content/6/2/e543.full.html\#\#ref-list-1

This article has been cited by 5 HighWire-hosted articles:

http://nn.neurology.org/content/6/2/e543.full.html\#\#otherarticles

Information about reproducing this article in parts (figures,tables) or in its entirety can be found online at:

http://nn.neurology.org/misc/about.xhtml\#permissions

Information about ordering reprints can be found online: http://nn.neurology.org/misc/addir.xhtml\#reprintsus

Neurol Neuroimmunol Neuroinflamm is an official journal of the American Academy of Neurology.

Published since April 2014, it is an open-access, online-only, continuous publication journal. Copyright

Copyright $\odot 2019$ The Author(s). Published by Wolters Kluwer Health, Inc. on behalf of the American Academy of Neurology.. All rights reserved. Online ISSN: 2332-7812.

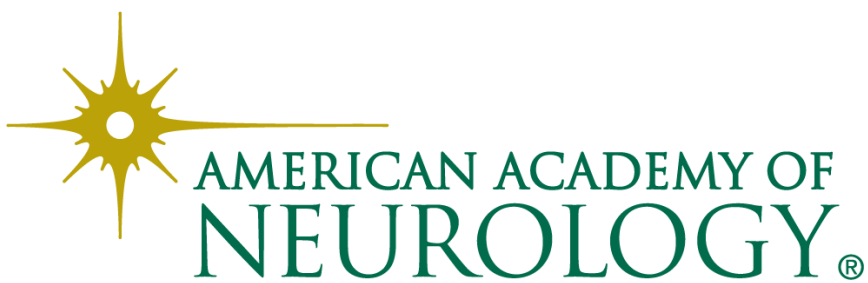

